\title{
Identification of peripheral CD154+ T-cells and HLA-DRB1 as biomarkers of acute cellular rejection in adult liver transplant recipients
}

Francisco Boix ${ }^{1}$, Isabel Legaz ${ }^{2}$, Rafael Alfaro ${ }^{3}$, Victor Jimenez-Coll ${ }^{3}$, Anna Mrowiec ${ }^{3}$, Helios Martinez-Banaclocha ${ }^{3}$, Jose A. Galian ${ }^{3}$, Carmen Botella ${ }^{3}$, Maria R. Moya-Quiles ${ }^{3}$, Francisco Sanchez-Bueno ${ }^{3}$, Ricardo Robles ${ }^{3}$, Jesus de la Peña-Moral ${ }^{3}$, Pablo Ramirez ${ }^{3}$, Jose A. Pons ${ }^{3}$, Alfredo Minguela ${ }^{3}$, and Manuel Muro ${ }^{3}$

${ }^{1}$ University Hospital of Salamanca

${ }^{2}$ University of Murcia Faculty of Medicine

${ }^{3}$ Virgen de la Arrixaca University Hospital

June 5, 2020

\begin{abstract}
Decreasing graft rejection and increasing graft and patient survival are great challenges facing liver transplantation (LT). Different T-cell subsets participates in the acute cellular rejection (ACR) of the allograft. Cell-mediated immunity markers of the recipient could help to understand the mechanisms underlying acute rejection. This study aimed to analyse CD4+CD154+ and CD8+CD154+ T-cells in a cohort of adult liver patients undergoing LT to determine the influence on ACR using multiparametric flow cytometry functional assay. Thiry patients were immunologically monitored at baseline and during 1 year post-transplant. Two groups were established, with (ACR) and without (NACR) acute cellular rejection. Leukocyte, total lymphocyte, percentages of CD4+CD154+ and CD8+CD154+ T-cells, HLA mismatch between recipient-donor and their relation with ACR as well as the acute rejection frequencies were analysed. T-cells were stimulated with concanavalin A (Con-A) and surface antigens were analysed by FACS analysis. A high percentage of CD4+CD154+ T-cells $(p=0.001)$ and a low percentage of CD8+CD154+ T-cells $(\mathrm{p}=0.002)$ at baseline were statistically significant in ACR. A receiver operating characteristic analysis determined the cut-off values capable to stratify patients at high risk of ACR with high sensitivity and specificity for $\mathrm{CD} 4+\mathrm{CD} 154+(\mathrm{p}=0.001)$ and CD8+CD154+ T-cells $(\mathrm{p}=0.002)$. In logistic regression analysis, CD4+CD154+, CD8+CD154+ and HLA mismatch were confirmed as independent risk factors to ACR. Post-transplant percentages of both T-cell subsets were significantly higher in ACR, despite variations compare to pre-transplant. These findings support the selection of candidates for LT based on the pre-transplant percentages of CD4+CD154+ and CD8+CD154+ T-cells in parallel with other transplant factors
\end{abstract}

\section{Hosted file}

Manuscript CD154+ T-cells in liver transplantation.doc available at https://authorea.com/ users/330183/articles/457063-identification-of-peripheral-cd154-t-cells-and-hla-drb1-asbiomarkers-of-acute-cellular-rejection-in-adult-liver-transplant-recipients 


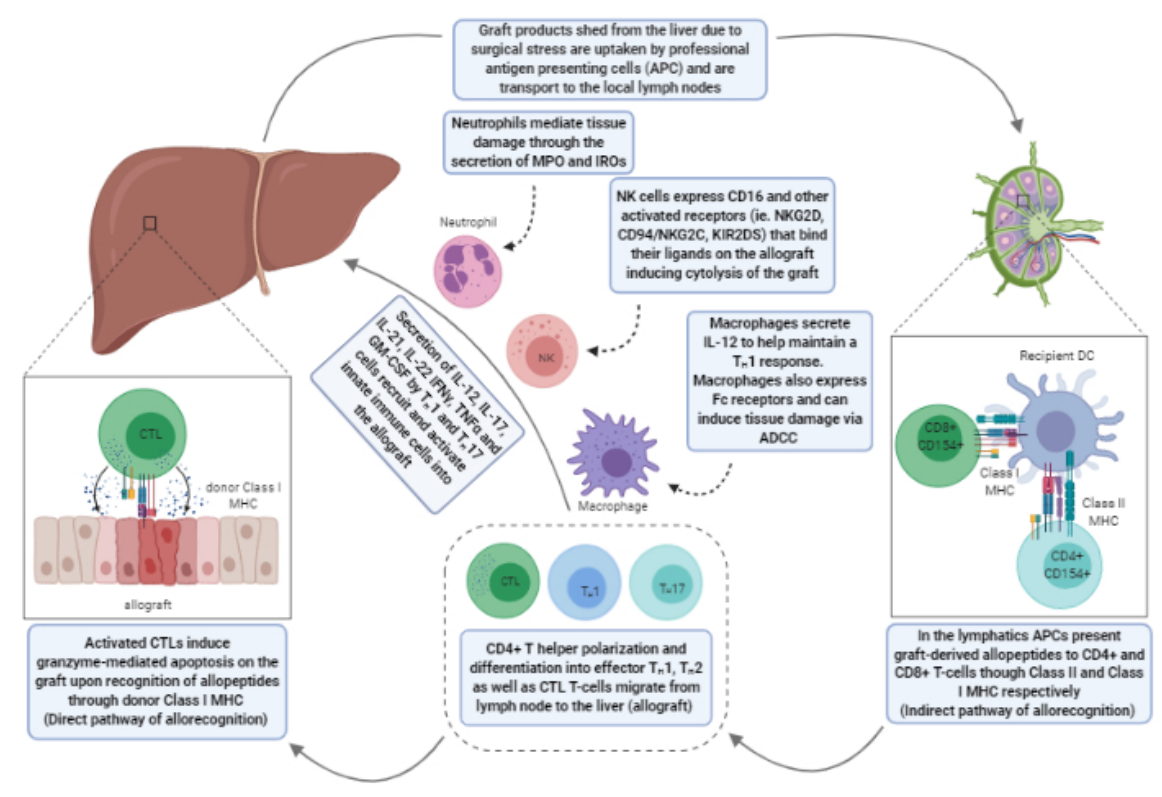

